\title{
A COMPACT HIGH POWER MICROWAVE (HPM) SOURCE
}

\author{
V.G.Baryshevsky* ${ }^{\dagger}$, A.E.Borisevich* ${ }^{\dagger}$, A.A.Gurinovich* ${ }^{\dagger}$, G.Yu.Drobyshev*, P.V. Molchanov* ${ }^{\dagger}$, \\ A.V.Senko*
}

\author{
*Research Institute for Nuclear Problems, \\ 11 Bobruiskaya str., Minsk 220050, Belarus, e-mail:gur@inp.minsk.by, fax: +375172265124 \\ ${ }^{\dagger}$ Private Research and Production Company «Electrophysical Laboratory» \\ 15 Smolenskaya Str., Minsk 220088,Belarus
}

Keywords: high power microwave, pulsed power source, Marx generator

\begin{abstract}
A compact high power microwave (HPM) source is reported. It generates short pulses by direct excitation of an antenna with a $300 \mathrm{kV}$ Marx generator. Oil insulation is used to protect capacitor banks from breakdown, while discharge gaps are designed to work in air. The Marx generator risetime is less than $50 \mathrm{~ns}$. The disk-cone antenna is also oilinsulated and operates in the self-breakdown regime. Radiated pulse has the duration about $2 \mathrm{~ns}$ and the spectrum from 800 $\mathrm{MHz}$ to $2 \mathrm{GHz}$. The HPM source is used for studying the vulnerability of computers and different electronic components.
\end{abstract}

\section{Introduction}

HPM has emerged as a new technology allowing new applications and offering innovative approaches to existing applications $[1,2]$.

An HPM source generates short high-power electromagnetic pulses able to disrupt or destroy electrical and electronic systems our society is rapidly becoming more and more dependent on. The infrastructure vulnerability (computers, communication systems, electronics of a car, etc.) is suspected, but is not definitely known. Simulators and test facilities for evaluating the HPM effect on electronics could provide the missing data and enable one to explore the protective measures. A range of HPM sources from small autonomous systems [3-6] to large high power devices [7, 8] have been developed.

A compact HPM source is reported. It generates short pulses by direct excitation of an antenna with a $300 \mathrm{kV}$ Marx generator. Oil insulation is used to protect capacitor banks from breakdown, while discharge gaps are designed to work in air. The Marx generator rise-time is less than $50 \mathrm{~ns}$. The disk-cone antenna is also oil-insulated and operates in the self-breakdown regime. Radiated pulse has the duration about $2 \mathrm{~ns}$ and the spectrum from $800 \mathrm{MHz}$ to $2 \mathrm{GHz}$. The HPM source is used for studying the vulnerability of computers and different electronic components.

\section{The HPM source components}

\subsection{Marx generator}

The Marx generator has ten stages, each containing four high voltage capacitors K $73-14$ (capacity $3.3 \mathrm{nF}$, operation voltage $25 \mathrm{kV}$, length $70 \mathrm{~mm}$, diameter $25 \mathrm{~mm}$ ) pairwise in series and then two pairs in parallel. The total capacity of the Marx generator is $330 \mathrm{nF}$. The stages are coupled through 510 $\mathrm{kOhm}$ resistors pairwise in parallel. Discharge gaps are made of steel balls of $30 \mathrm{~mm}$ diameter with the $11 \mathrm{~mm}$ gap for the first one and $18 \mathrm{~mm}$ for the others. All the elements are installed on a plexiglas plate so as the capacitors and resistors, which should be drowned in oil, appear under the plate, while the discharge gaps are on top to work in air. The plexiglas plate with the assembled circuit placed into the polyethylene container ( $850 \mathrm{~mm} \times 400 \mathrm{~mm} \times 170 \mathrm{~mm}$ ) half-filled with oil. Four supporting legs keep the top surface of the plate above the oil-level.

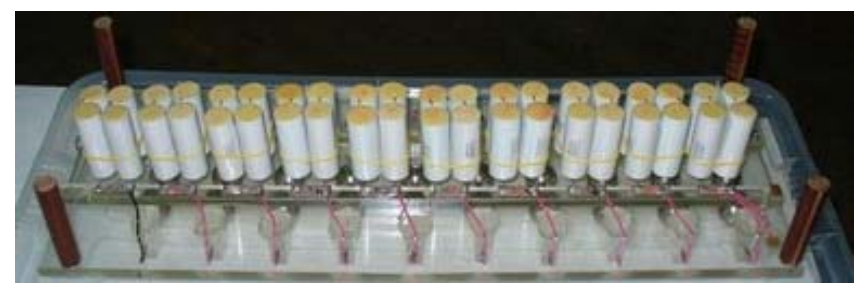

Fig.1. Marx generator (bottom view)

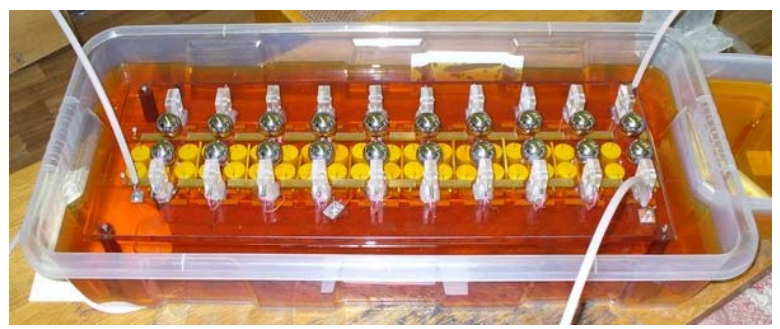

Fig.2. Marx generator (top view)

The output voltage of the Marx generator is measured by the accurate measuring discharge gap as high as $300 \mathrm{kV}$. The Marx generator rise-time is less than $50 \mathrm{~ns}$. 


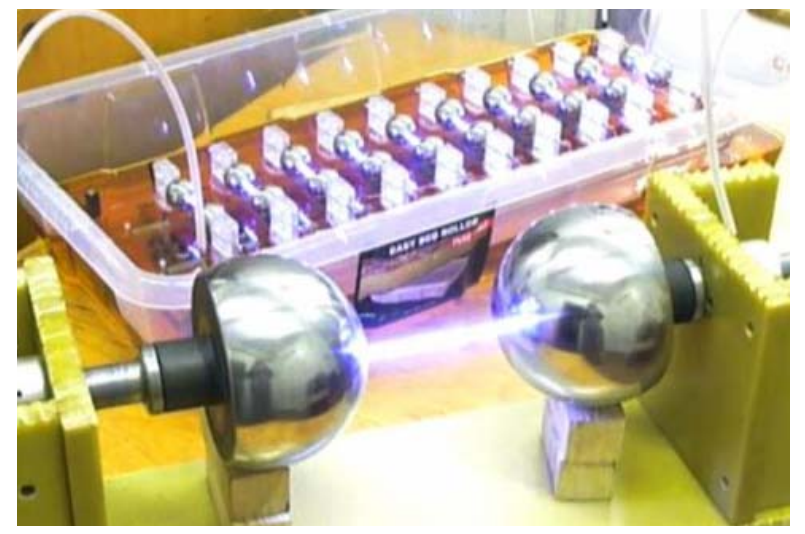

Fig.3. Breakdown of the accurate measuring discharge gap

\subsection{Antenna}

The disk-cone antenna with an integrated discharge gap is designed for operation in the range from $800 \mathrm{MHz}$ to $2 \mathrm{GHz}$. The cone with the angle $70^{\circ}$ is made of tin and placed under the steel plate. The discharge gap is formed by the steel ball and tungsten plate; it is oil-insulated and operates in the selfbreakdown regime. The antenna is placed at the focal point of the dish reflector $1.6 \mathrm{~m}$ in diameter. A convergent mirror is used for optimization of the antenna yield. The dish reflector and convergent mirror direct and amplify the signal from the antenna in the prescribed direction simultaneously keeping it off electromagnetic pulses from other sources (for example, discharge gaps of the Marx generator).
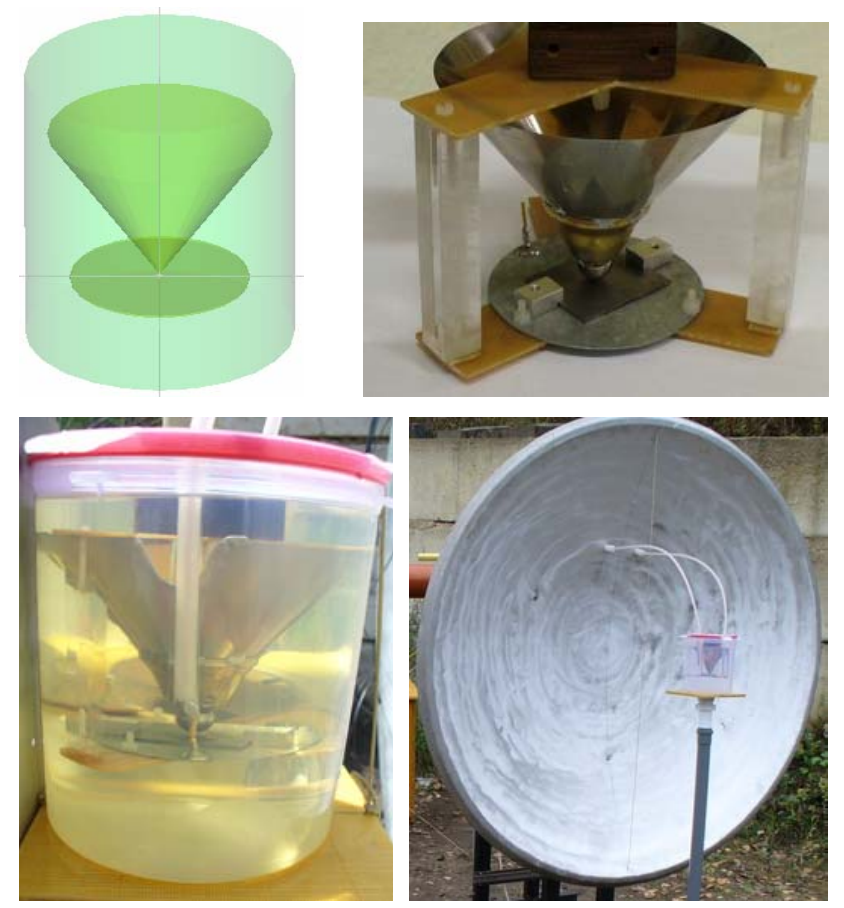

Fig.4. Antenna design

Antenna diagrams are calculated for $700 \mathrm{MHz}, 1$ and $1.5 \mathrm{GHz}$ to define experiment layout and evaluate the electric field strength. The main lobe magnitude is $19.3,21.1$ and 22.5 $\mathrm{dBi}$, while the main lobe angular width $(3 \mathrm{~dB})$ is $16.4^{\circ}, 10.7^{\circ}$ and $5.4^{\circ}$, respectively.
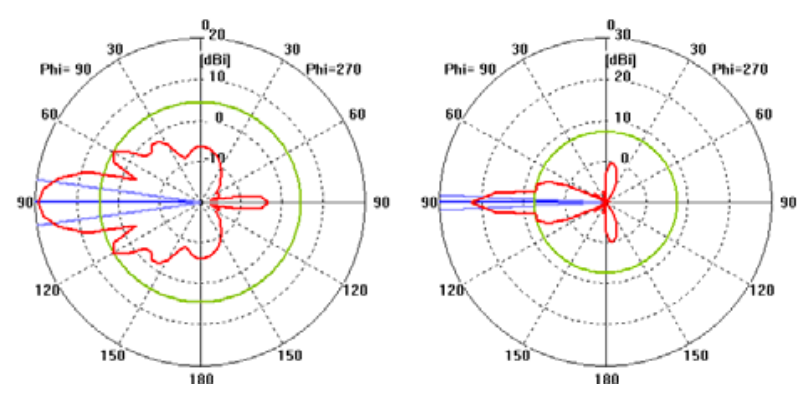

Fig.5. Calculated antenna diagrams for $700 \mathrm{MHz}$ (left) and $1.5 \mathrm{GHz}$ (right).

\section{Experiment}

\subsection{Experiment layout}

The HPM source is studied at a testing area to avoid signal rescattering and gain access to the areas with significantly different values of the electric field strength, which linearly decreases with the growth of the distance from the antenna.

Field probes (measuring antennas Geozondas GZ031ANL-2 and D-dot Prodyn probes AD-S110(R)) are placed at the distance 30 meters from the radiating antenna and connected to the Tektronix TDS7704B digital oscilloscope hidden in a shielded room and operated from an uninterruptible power supply.

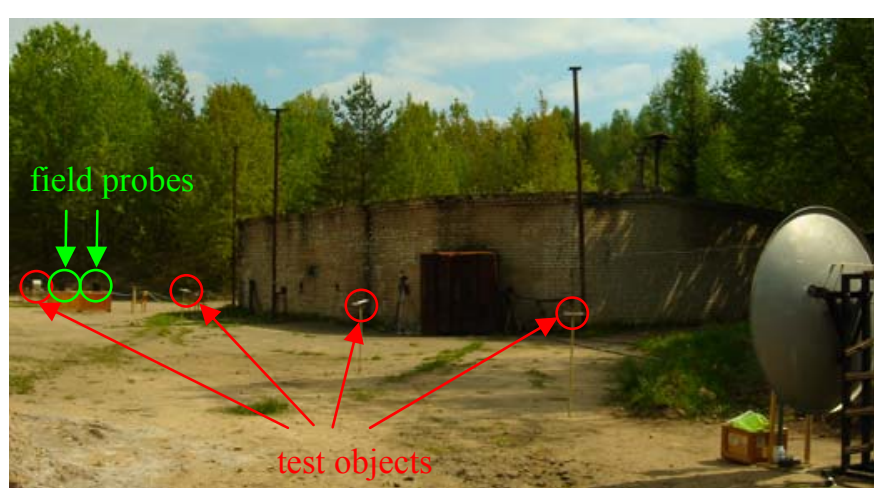

Fig.6. Experiment layout
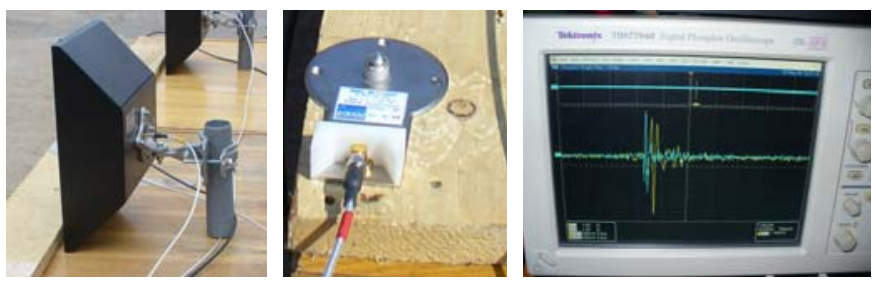

Fig.7. Measuring antenna GZ031ANL-2, D-dot Prodyn probe AD-S110(R) and digital oscilloscope with the detected radiation pulse on the screen. 
Different test objects are distributed along the main lobe direction at the distance 5, 10, 15 and 25 meters from the antenna. The desktop computer is placed as far as 40 meters from the HPM source.

Test objects are the elements of analog and analog-digital dynamic circuits (for example, relaxation oscillator) specially developed for such experiments. LEDs in these circuits make circuit drop-in visible.
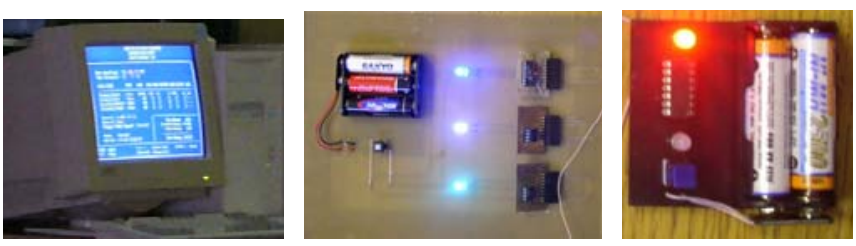

Fig.8. Test objects

\subsection{Experiment results}

Radiated pulse has the duration about $2 \mathrm{~ns}$ and the spectrum from $800 \mathrm{MHz}$ to $2 \mathrm{GHz}$.

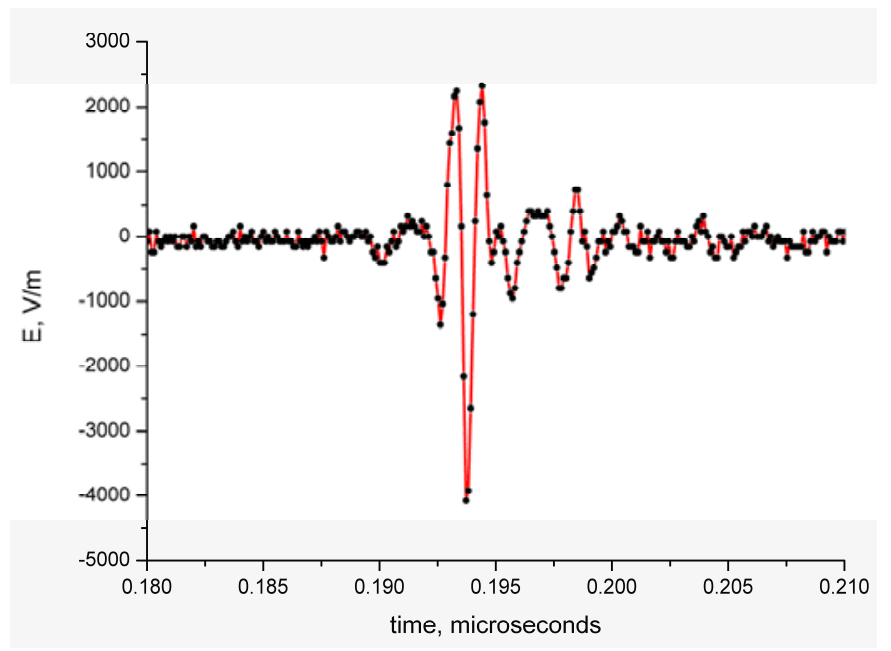

Fig. 9. The typical signal from D-dot probe

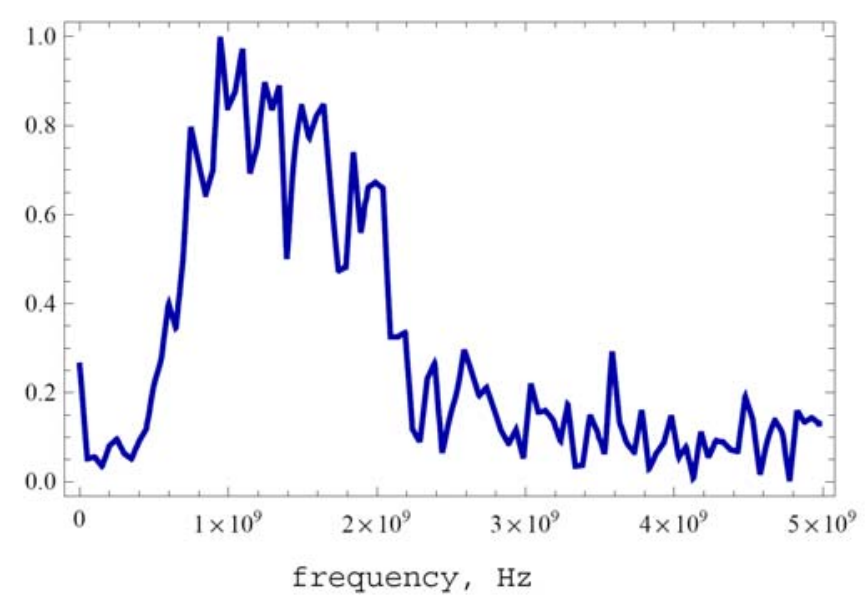

Fig.10. The signal spectrum
As the discharge gaps of the Marx generator operate in air the amplitude of the signal depends on the environmental conditions (humidity, dust and so on) and varies from $6.5 \mathrm{kV} / \mathrm{m}$ to $3 \mathrm{kV} / \mathrm{m}$ at a distance of 30 meters from the antenna in different tests. The signal amplitude also depends on the properties of oil filling the antenna discharge gap and the gap. Placing test objects at different distances from the antenna makes it possible to test them with different electric field strength.

Computers and their components are the most popular test objects. A variety of damage effects are described by different authors [9-11]. Depending of pulse amplitude three types of damage are detected for a desktop computer 40 meters away from the antenna: stopping, reload and switching off. Test objects distant differently from the antenna also demonstrate several types of failure: logical (an oscillator changes its frequency), temporary malfunction and permanent failure.

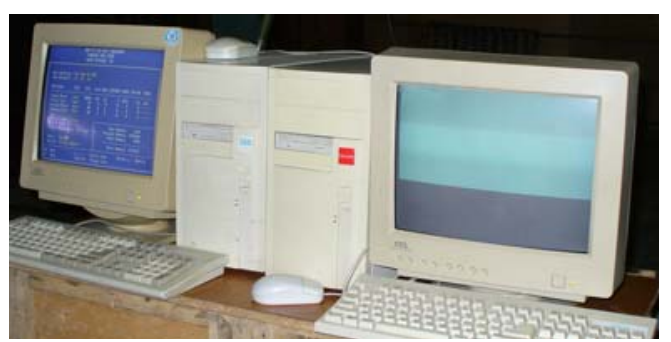

Fig.11. Different damage effects are detected for desktop computers: stopping (left computer, the clock in BIOS stops, operation restores after reload), graphics card malfunction

(right computer, operation restores in several hours).

\section{Conclusion}

The developed HPM source is compact and easy-to-use. It allows one to test different electronic components and devices for HPM effect both in the laboratory and at the testing area simulating diverse cases of interest in the wide range of electric field strength in the frequency range from $800 \mathrm{MHz}$ to $2 \mathrm{GHz}$.

\section{References}

[1] J. Benford, J. A. Swegle, E Schamiloglu "High Power Microwaves", Taylor \& Francis (2007).

[2] D.V.Giri, "High-Power Electromagnetic Radiators, NonLethal Weapons and Applications", Harvard University Press, (2004).

[3] J.Tatoian, D.Giri, G.Franceschetti, G.Gibbs "High Power Microwave System for Stopping Vehicles" Euroem'2004 Magdeburg, Germany, (2004).

[4] R.H. Stark, J. Urban, C. Bickes, V. Kadetov, D. Weixelbaum, E. Mutzbauer "Pulsed Power Technology for HPEM Application” EUROEM'2008, Lausanne, Switzerland, (2008). 
[5] A. Tehori, J. Statlender, A.Tokarsky "Electromagnetic Vehicles Immobilization System (ELVIS)" EUROEM'2008, Lausanne, Switzerland.

[6] Benoît Martin, Philippe Delmote "The GIMLI: a compact High-power UWB radiation source" EUROEM'2008, Lausanne, Switzerland, (2008).

[7] Robert L. Gardner "Methods to Determine the Effect of Pulse Width on Susceptibility Threshold Levels" EUROEM'2008, Lausanne, Switzerland, (2008).

[8] V.B. Carboni, H.J. Kishi, T.M. DaSilva, T.W. Tatman, I.D. Smith, C.C.R. Jones, N.R.M. Ritchie, S.I. Richmond "Full Threat Level Transportable Lightning Simulation System" EUROEM'2008, Lausanne, Switzerland, (2008).

[9] S.M.Hwang, J.I.Hong, and C.S.Huh "Characterization of the susceptibility of integrated circuits with induction caused by high power microwaves", Progress In Electromagnetics Research, PIER 81, pp.61-72, (2008).

[10] M.Camp, H.Garbe, D.Nitsch, "UWB and EMP Susceptibility of Modern Electronics", IEEE EMC, Montreal, August 13-17, 2001, ISBN: 0-7803-6569-0, pp. 1015-1020, (2001).

[11] D.Nitsch, M.Camp, "UWB and EMP Susceptibility of Modern Microprocessorboards", EMC Europe, Brugge, Sept. (2000). 